\title{
Cleaner urban air tomorrow?
}

\author{
Air pollution in large cities remains a persistent public health problem. Adapting air quality forecasts for \\ use by decision makers could help mitigate severe pollution events.
}

Beijing may be the poster child for air pollution, but Delhi, where air pollution causes up to 30,000 premature deaths annually, has earned the dubious distinction of being the most polluted megacity in the world $^{1}$. Late last year, Delhi's already bad air quality became worse. Emissions from coal-fired power plants or vehicles were not responsible; instead it was fireworks set off to celebrate the annual Hindu festival of Diwali. The Diwali fireworks are known to cause large increases in particulate matter and metal in the atmosphere $e^{2,3}$. Last year, the pollution they caused was compounded by emissions from agricultural biomass burning. Visibility was extremely poor, schools were closed for days and hospitals experienced a flood of respiratory-related visits.

Severe urban air pollution is not limited to developing economies. Approximately 9,500 London residents die prematurely each year as a consequence of air pollution ${ }^{4}$. In December, Paris experienced its worst air pollution event of the decade. Widespread barbecuing during football matches has been blamed for $25 \%$ of air quality alerts in Santiago, Chile over the past couple of years. And this year's New Year's Eve fireworks were associated with doubled particulate matter concentrations in Munich and other German cities, many times in excess of recommended levels.

Cities such as Paris, Mexico City, Madrid and Athens have commited to banning diesel vehicles entirely by 2025 , and some are instituting partial restrictions in the meantime (http://urbanaccessregulations.eu/). More flexible car bans have been adopted elsewhere: Beijing famously banned half of all vehicles from driving in the city during the 2008 Olympics; now $20 \%$ are banned each day in a policy similar to the one that Mexico City instituted in 1989, which failed to improve air quality ${ }^{6}$.

Attempts to address part of the air quality problem by reducing overall emissions do not, however, address the role of meteorology. Ultimately, the weather can determine whether or not air pollution becomes severe; it does not just matter where emissions occur, but when they occur. In Beijing, winter is the season for pollution not only because there are increased emissions associated with heating,

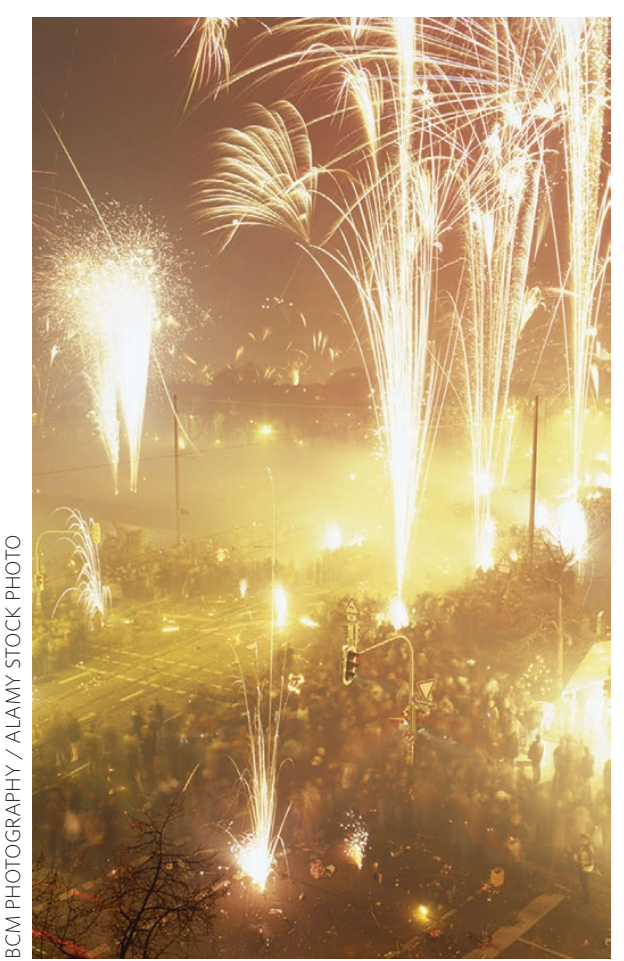

New Year's Eve fireworks in Munich contribute to air pollution in excess of health guidelines.

but because atmospheric inversions that trap pollution in the city are more common at that time of year.

A more nimble, dynamic approach than blanket emissions reductions is therefore likely to be more efficient in mitigating severe instances of poor air quality. Cities have shown that they can respond quickly to pollution once it is underway. During the December smog, Paris banned half of all vehicles from the city for three days straight and made public transport free. Madrid instituted a similar ban for the first time in its history when it was hit with heavy pollution a few weeks later. But these policies are all reactive. With improvements in modelling, we may soon be reaching the point when air quality can be forecast sufficiently well to prevent severe pollution before it kicks in. Simulations of near-term emissions, weather and atmospheric chemistry that assimilate data from observation networks to correct for model bias are not far off from having the capability to provide cities with a reliable prediction tool.

Near-term forecasts have long been used to alert citizens about poor air quality, and forecasts are becoming more reliable in the 24-48 hour range. Some systems go further: in Barcelona, the CALIOPE system provides forecasts that incorporate different emission reduction scenarios such as vehicle bans (http://www.bsc.es/caliope/es). As such, CALIOPE and systems like it have the necessary functionality to provide decision makers with the information they need take preventive action.

Preventive restrictions could prove politically tricky. After all, if short-term restrictions in emissions succeed in mitigating a severe air pollution event, there is not much a politician can point towards to explain how much worse it could have been. As forecast uncertainty rises with lead time, imposing emission restrictions might only be politically palatable in the very short term, which could reduce their effectiveness for mitigating pollution. But if a forecast is wrong, cities pay a real economic and social cost for imposing early preventive restrictions without a benefit. Certainly lessons can be learned from the history of decision making in cities faced by threats from hurricanes: those cities must decide whether and when to evacuate a city based on forecasts, and those decisions have a host of conflicting political, social, economic and public health implications.

To be successful, forecast-driven regulatory policy needs a government willing to risk the potential costs of restrictive actions and reliable forecasts that are designed specifically as decision-making tools, with appropriate uncertainty alerts. Developing effective systems will probably require considerable collaboration between air quality modellers, decision makers and policy and public health experts. But it is an effort that could reap substantial public benefits.

\footnotetext{
References

1. Global Urban Ambient Air Pollution Database (World Health Organization, 2016); http://go.nature.com/2j16ahw

2. Mandal, P. et al. Environ. Monit. Assess. 184, 209-215 (2011).

3. Kulshrestha, U. C. et al. Atmos. Environ. 38, 4421-4425 (2004).

4. Walton, H. et al. Understanding the Health Impacts of Air Pollution in London (Kings College London, 2015).

5. Schmidt, C. W. Environ. Health Persp. 124, A19-A22 (2016).

6. Davis, L. W. J. Polit. Econ. 116, 38-81 (2008).
} 